\title{
Bora-induced currents corresponding to different synoptic conditions above the Adriatic
}

\author{
G. Beg Paklar ${ }^{1}$, A. Bajić ${ }^{2}$, V. Dadić ${ }^{1}$, B. Grbec ${ }^{1}$, and M. Orlić ${ }^{3}$ \\ ${ }^{1}$ Institute of Oceanography and Fisheries, Šet. I. Meštrovića 63, 21000 Split, Croatia \\ ${ }^{2}$ Meteorological and Hydrological Service of Croatia, Grič 3,10000 Zagreb, Croatia \\ ${ }^{3}$ Andrija Mohorovičić Geophysical Institute, Faculty of Science, University of Zagreb, Horvatovac bb, 10000 Zagreb, Croatia
}

Received: 21 December 2002 - Revised: 14 February 2005 - Accepted: 24 February 2005 - Published: 3 June 2005

\begin{abstract}
The Bora wind field is characterised by strong vorticity and divergence. Several numerical experiments, in which an oceanographic model was forced with northeasterly winds having climatological alongshore variability, were performed in order to study the influence of spatial variability in the bora wind field on the surface currents in the northern Adriatic. Numerical model results showed that during bora episodes with lower speeds and fast offshore decay surface currents along transect Rovinj - Po River are predominantly in the downwind direction. On the other hand, during bora episodes with strong intensity and slow offshore decay, a cyclonic gyre due to the pronounced bora alongshore variability is formed in the northernmost part of the Adriatic Sea and the studied transect is influenced by the counter currents. Moreover, bora having a high speed and a short offshore range produces the same effect in the eastern part of the Rovinj Po River transect as low-speed bora characterised by slow offshore decay.

Eulerian current measurements performed in the northern Adriatic during bora episodes characterised by different synoptic conditions supported the numerical model findings. Surface currents during the bora episode of 8-11 February 1984 were directed downwind, whereas during the episode of 12-19 February 1984 they were directed upwind. The first episode was characterised by a deep bora layer with cyclonic activity over the western Mediterranean and Genoa Bay, whereas the second one was accompanied by temperature inversion and a southwesterly tropospheric wind above a shallow bora layer. According to the hydraulic theory developed by Smith (1985), an observed descent of isentropes during the second bora episode led to the stronger acceleration in the bora layer and its larger offshore extent. Different offshore bora decays during studied events were confirmed by a comparison of the wind data originating from the meteorological stations positioned on the opposite Adriatic coasts.
\end{abstract}

Correspondence to: G. Beg Paklar

(beg@jadran.izor.hr)
Keywords. Oceanography: Physical (Air-sea interaction, Currents, Numerical modelling)

\section{Introduction}

Bora (in Croatian this wind is known by the name bura) is a strong and cold katabatic wind that blows along the eastern Adriatic coast from the northeastern quadrant. There have been many studies and descriptions of wind regime and bora wind characteristics on the northern Adriatic in the last few decades. One of the most comprehensive reviews of the borarelated research can be found in Yoshino (1976), where bora was considered from a climatological, synoptic and aeorological point of view. It is well known that bora occurs under various synoptic conditions (Yoshino, 1976; Jurčec, 1989) and both observational and modelling studies show that the strongest bora cases occur during winter, being related to the frontal passages from the northwest and cyclones moving along the Adriatic to the southeast (Brzović, 1999).

A great step forward in the understanding of bora dynamics was provided by Smith's results from both observational studies of ALPEX (ALPine EXperiment) bora cases (Smith, 1987) and the theoretical approach to downslope wind structure based on hydraulic theory (Smith, 1985; Smith and Sun, 1987). Hydraulic theory is a steady-state hydrostatic theory, which describes the flow of fluid over an obstacle, and one of its solutions is a flow accelerated in both the upstream and downstream region leading to the occurrence of severe wind on the lee side. Upstream acceleration, obtained both from aerological and aircraft measurements (Smith, 1987), is the result of descending critical isentrope and accompanying increasing temperature gradients in the downstream direction (Smith, 1985). Smith's analytic model links downslope windstorms to the breaking waves in a continuously stratified atmosphere by solving Long's (1954) equation. Studies of Bajić (1988) and Vučetić (1988) have shown that the application of the hydraulic theory is successful in the case of the postfrontal bora type, whereas Jurčec (1988) has shown 

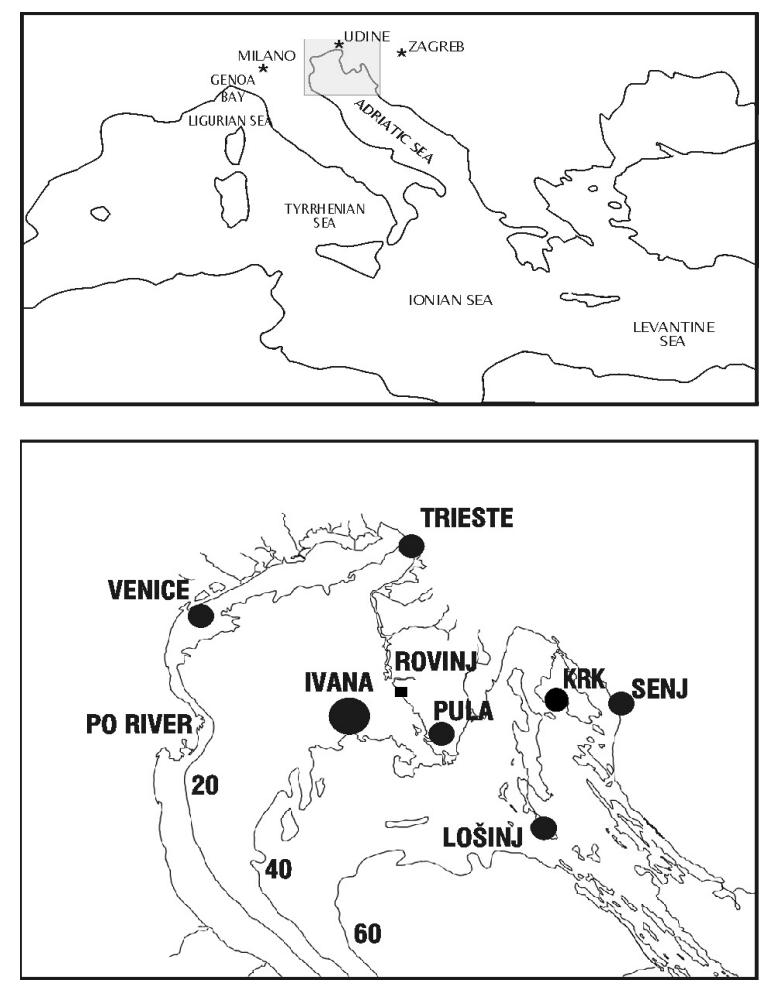

Fig. 1. Northern Adriatic Sea location and bathymetry. The locations of the radio-sounding stations are denoted in the upper chart with asterisks, whereas the locations of the gas field Ivana and meteorological stations whose data were used in the analysis are denoted with full circles on the lower chart.

the same in the case of the frontal type. The strongest bora cases are connected with oppositely directed air flow above the bora layer, whereas in the cases with northeasterly upper wind the surface bora is weaker (Jurčec, 1989).

The pronounced alongshore variability in the bora wind speed is mainly controlled by the mountain chain along the eastern coast, whereas offshore bora extension depends on the synoptic situation and the intensity of the cold air outbreak across the Dinaric Alps. Although surface data characteristics in the coastal area as well as vertical profiles were extensively analysed, only a few studies of the offshore bora spreading in the northern Adriatic exist. Polli (1956) has found that during the strong events bora decreased by about $60 \%$ from Trieste to Venice. Investigations by Yoshino et al. (1976) of wind-shaped trees revealed that at some locations strong bora areas disappear at $20 \mathrm{~km}$ distance off shore. Analysis of wind data at coastal and open sea stations in the southern Adriatic area showed different offshore wind decrease regimes during different synoptic situations (Miljak, 1982, in Penzar et al., 2001). Due to the lack of open sea meteorological stations, a similar analysis is missing for the northern Adriatic. Climatological analysis of the bora wind field pointed to bora frequencies decreasing in the offshore direction (Makjanić, 1978). Numerical experiments by Enger and Grisogono (1998) showed the controlling influence of the sea surface and air temperature differences on the off- shore bora spreading. In the case of higher sea surface than air temperature the bora occupies a larger offshore area. This result requires observational support.

The measurements of the bora have shown that at some locations the hourly average surface wind reaches $17 \mathrm{~ms}^{-1}$ and gusts exceed $50 \mathrm{~ms}^{-1}$ (Bajić and Glasnović, 1999). The analyses of simultaneous wind and current measurements obtained at a gas field positioned in the northernmost part of the Adriatic $70 \mathrm{~km}$ off Trieste indicated that bora with an hourly mean of about $10 \mathrm{~ms}^{-1}$ generates in the Adriatic surface currents of up to $50 \mathrm{cms}^{-1}$ and bottom currents of up to $30 \mathrm{~cm}^{-1}$ (Orlić et al., 1986). Horizontal variability of the current field is primarily influenced by the wind-curl effect. The bora influence on the Adriatic current field was studied in some detail during the winter homogeneous period from empirical in-situ (Zore-Armanda and Gačić, 1987) and remotely sensed data (Kuzmić, 1991; Sturm et al., 1992). Numerous numerical models successfully reproduced either semicircular (Stravisi, 1977) or full cyclonic gyre (Orlić et al., 1986; Bone, 1993; Orlić et al., 1994; Beg Paklar et al., 2001; Pullen et al., 2003) induced by the bora in the northernmost part of the Adriatic.

Influence of vorticity and divergence of the bora wind field on the surface currents is studied in this paper using an oceanographic model forced by winds having a climatological alongshore profile with various intensities and offshore ranges. Eulerian current measurements performed during the period 19 January-19 February 1984 at the gas field Ivana in the northern Adriatic (Fig. 1), together with the wind data from several meteorological stations positioned on the opposite Adriatic coasts, are used as a possible support of the numerical model findings. Also given is a detailed analysis of two synoptic situations with bora episodes.

\section{The numerical model results}

Several numerical experiments were performed in order to examine the influence of the bora wind field spatial variability on the surface currents of the northern Adriatic. Numerical experiments were made with the Princeton Ocean Model (POM) (Blumberg and Mellor, 1987). POM is a three-dimensional primitive equation nonlinear model with complete thermodynamics. The equations which capture the model physics are the traditional equations for the conservation of mass, momentum, heat and salt coupled with the equation of state (Mellor, 1991). The model contains a second order turbulence closure submodel "level 2 1/2" described in the Mellor and Yamada (1982) review, which provides two prognostic differential equations for the turbulence kinetic energy and turbulence macroscale. The horizontal viscosity and diffusivity coefficients are obtained using the horizontal diffusion formulation following J. Smagorinsky, adapted to the sigma coordinate system (Mellor and Blumberg, 1985). The model employs a staggered C-grid according to A. Arakawa and a bottom following sigma coordinate in the vertical direction. The leapfrog scheme is used 
for time stepping and a central difference scheme is used for spatial terms. The horizontal time differencing is explicit, whereas the vertical diffusion differencing is implicit.

In the simulation of bora influence on the Adriatic, a rectangular grid with $10-\mathrm{km}$ resolution in the horizontal plane and 16 sigma levels in the vertical direction was used. The numerical model domain is shown in Fig. 2. The horizontal grid spacing is constant, whereas the vertical spacing varies in order to achieve better resolution near the surface and bottom. The topography of the studied area was digitised from the bathymetric chart B100 given in Mercator projection (Croatian Hydrographic Institute, Split), and smoothed with a Shapiro (1970) filter. In the numerical experiments an external time step of $70 \mathrm{~s}$ and an internal time step of $1400 \mathrm{~s}$ satisfied the Courant-Friedrichs-Lewy stability criterion. The model was integrated for 10 days in each experiment in order to reach the steady state.

POM was forced with the winds of the northeastern direction having a climatological profile in the alongshore direction (Fig. 2, after Orlić et al., 1994). The wind stress was determined using a bulk coefficient approach with the drag coefficient according to Deacon and Webb (1962). In all the experiments we assumed a linear decrease of the wind speed in the offshore direction. Differences between 30 performed experiments were in the bora wind speed and distances from the eastern shore at which the wind speed vanished. The effect of the variable wind stress curl was investigated by forcing the model with climatological profiles calibrated to wind speeds of 5,10 and $15 \mathrm{~m} / \mathrm{s}$ at the Pula meteorological station (Orlić et al., 1994). For each of these profiles the wind speed equalled zero at $30 \mathrm{~km}, 40 \mathrm{~km}$, etc., up to $150 \mathrm{~km}$ from the eastern shore.

Surface currents and those at the seventh sigma level obtained in the experiments with a profile calibrated to a wind speed of $10 \mathrm{~m} / \mathrm{s}$ at the Pula station indicate that the current direction at transect Rovinj - Po River depends on the wind speed decrease from the eastern coast (Fig. 3). In the experiments with a large decrease, surface current at the studied transect is in downwind direction (Figs. 3a,b,c). On the other hand, in the experiments with a smaller decrease, the cyclonic gyre in the northernmost part of the Adriatic is generated and transect Rovinj - Po River is in the area of the counter current (Figs. 3d,e,f). Beside a general current strength decrease with depth, vertical homogeneity is increasing with the offshore bora range.

Since the results of the numerical experiments will be compared in the next section with current measurements at the gas field Ivana (Fig. 1), currents at model nodes corresponding to this position are presented in Fig. 4. Surface currents (Fig. 4a) and those from the seventh level (Fig. 4b) are shown for the experiments characterised by various wind speeds and fetches. Significant current variability in the area of the Ivana station can be explained by the existence and strength of the cyclonic gyre in the northernmost part of the domain and the small anticyclonic gyre further south. During the bora episodes with fast offshore decay and lower speeds, the double gyre system is not pronounced and the currents in

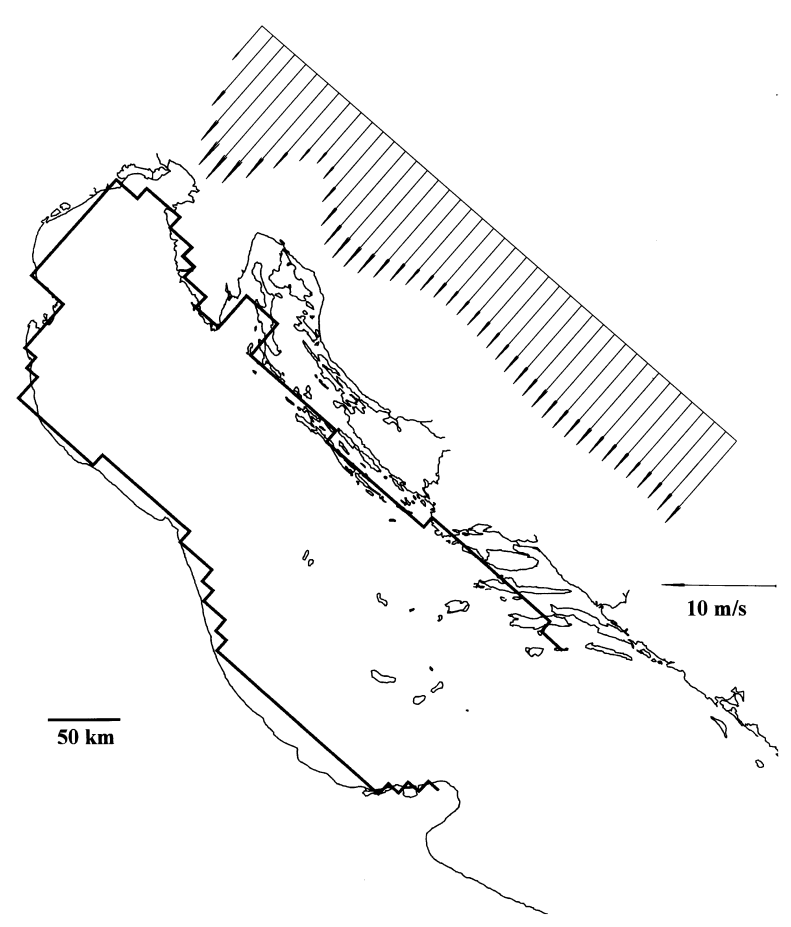

Fig. 2. Domain of the oceanographic model and the bora wind profile used in the numerical experiments.

the selected area are predominantly in the downwind direction. On the other hand, lower offshore decay and stronger wind intensity favour a double gyre structure and the studied area is influenced by the counter current. Moreover, currents for the lower winds and longer fetches are similar to those originating from experiments with the higher wind intensities and shorter fetches, since in these situations stresses acting on the sea surface are of comparable strength. Vertical current homogeneity is increasing with increased wind speed and offshore range.

\section{Bora episodes from winter 1984}

In order to support numerical model results we present Eulerian current measurements from the gas field Ivana in the northern Adriatic (Fig. 1, 44 $47^{\prime} \mathrm{N}, 13^{\circ} 25^{\prime} \mathrm{E}$ ), obtained during bora episodes related to different synoptic situations. Detailed analysis of synoptic situations, with a possible explanation of the bora-controlling mechanisms, is also given.

\subsection{Currents}

Current measurements analysed in this paper were carried out by Aanderaa RCM4 current meters. This type of instrument is one of the most frequently used in Croatia during the 1970s and 1980s. RCM4 current meters were widely tested and compared with other types of instruments (Gould, 1973; Sounders, 1976, 1980; Beardsley et al., 1981; Sherwin, 1988). The instruments' main errors, due to the compassrelated problems, vane response length scale, sampling rate 


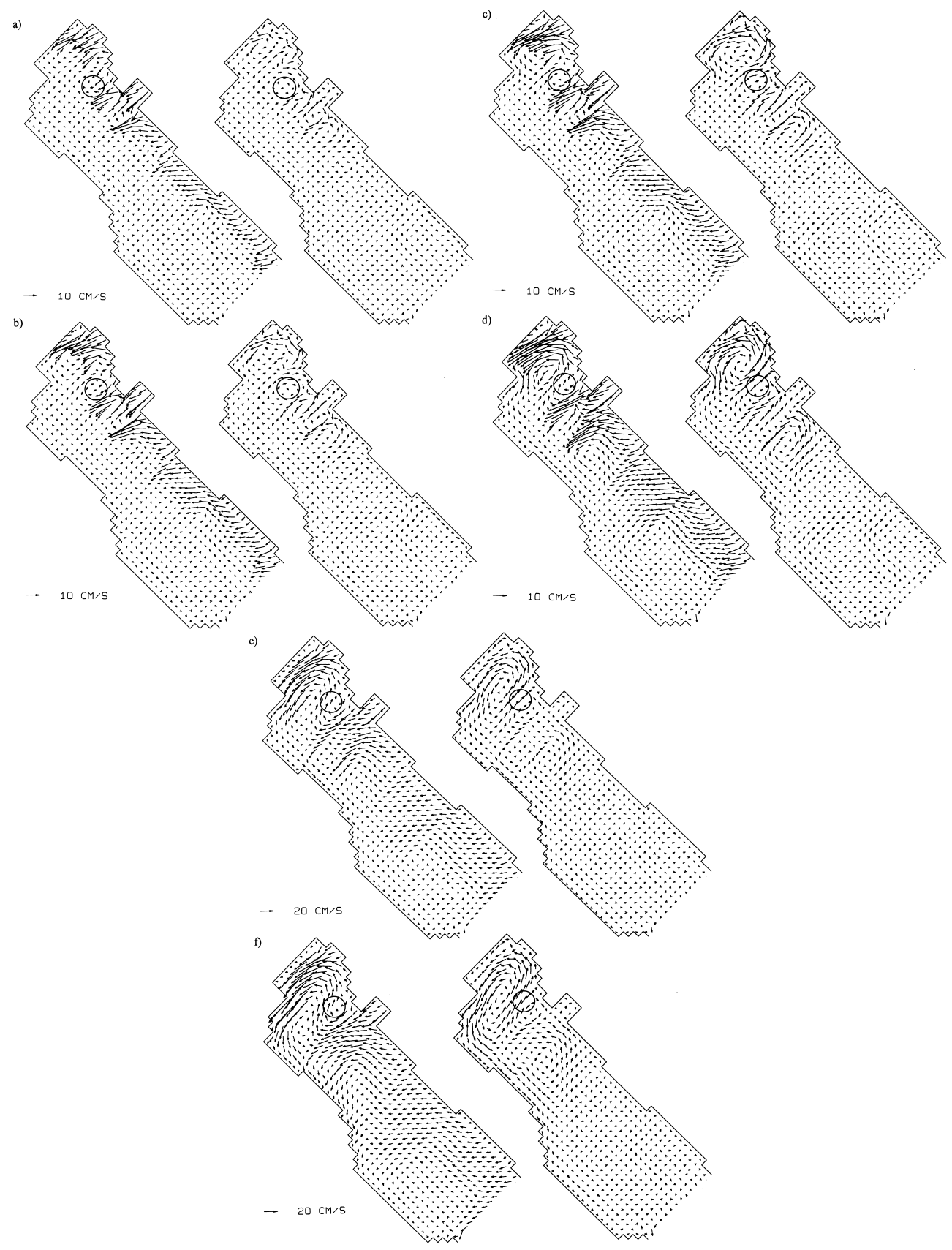

Fig. 3. Surface currents (left) and currents at the seventh sigma level (right) obtained from the numerical experiments assuming a bora range of $30 \mathrm{~km}(\mathbf{a}), 40 \mathrm{~km}(\mathbf{b}), 50 \mathrm{~km}(\mathbf{c}), 70 \mathrm{~km}(\mathbf{d}), 100 \mathrm{~km}(\mathbf{e})$ and $150 \mathrm{~km}(\mathbf{f})$ and a climatological profile calibrated to $10 \mathrm{~m} / \mathrm{s}$ at the Pula meteorological station. The gas field Ivana is denoted by a circle.

and wave influence, occur mostly with low currents and can be reduced by calibration prior to and after each deployment and by choosing appropriate methods of mooring.

Strong currents during studied bora events and special deployment reduced some of the RCM4 errors in our case. All current meters at the gas field Ivana were deployed from the oil exploration platform fixed by three steel legs at the sea bottom. Each RCM4 current meter hung on a separate synthetic rope (12 $\mathrm{mm}$ in diameter), protruding $4 \mathrm{~m}$ from the platform deck. To avoid the influence of steel on compass registration, the distance between the current meters and the platform legs was $25 \mathrm{~m}$. The described RCM4 deployment reduced the compass error, as well as errors induced by waves. According to Sherwin (1988), the latter error depends on the ratio of mean speed, wave speed and angle between their directions. During bora events with speeds ranging from 3.3 to $19.1 \mathrm{~ms}^{-1}$, wind waves having a height of $1.6 \mathrm{~m}$ and a period of $5.7 \mathrm{~s}$ are generated (Smirčić et al., 
1996), whereas surface currents could reach $50 \mathrm{cms}^{-1}$ (Orlić et al., 1986). Under these conditions wave-related surface current amplification is between 15 and 20\%. Current reversal, which is the main topic of our paper, could not be significantly affected by this amplification.

Surface current time series obtained in the period from 19 January to 19 February 1984 reveal the influence of two bora episodes (Fig. 5): A) 8-11 February and B) 12-19 February. Wind data were simultaneously collected at the Pula airport station (Fig. 1). Both wind and current hourly means were low-pass filtered with a $24 \mathrm{~m} 214$ filter (Thompson, 1983). The bora wind from 8 to 11 February, with a maximum lowpass filtered speed in Pula of about $6.5 \mathrm{~ms}^{-1}$, induced downwind currents in the surface layer at the gas field Ivana reaching $20 \mathrm{cms}^{-1}$ (Fig. 5). On the other hand, in the period from 12 to 19 February surface currents with a pronounced upwind component dominated. Maximum current speed in the period $\mathrm{B}$ was about $20 \mathrm{cms}^{-1}$. The corresponding maximum filtered wind speed at the Pula station was $8.5 \mathrm{~ms}^{-1}$ (Fig. 5).

\subsection{Synoptic situations}

Although bora wind blew during the whole period from 8 to 19 February, synoptic developments and accompanied bora characteristics were different in the 8-11 February and 1219 February intervals with strong bora decay between them. Consequently, the period mentioned could be considered to comprise two bora episodes with large differences in synoptic situations and their development. The crucial difference between the episodes (not easily noticeable in the surface pressure patterns) is the vertical atmospheric structure across the Dinaric Alps and Adriatic coast.

A) 8-11 February 1984. Synoptic development at the beginning of this situation was marked by a cold air outbreak and a deepening trough in Western Europe. Further largescale development had a usual sequence characterised by a cut-off process and displacement of the upper level ridge from Western Europe eastward (Jurčec, 1989; Bajić, 1988). A cyclone developed when a cold front, associated with a primary trough moving eastward over Europe, interacted with the Alps. At the surface, the cyclone reached maximum intensity around 12 UTC on 9 February, and then gradually filled. The upper level evolution showed the amplification of a trough over central Europe. Lee cyclogenesis appeared at higher levels as a cut-off forming up to $300 \mathrm{hPa}$. The upper cut-off low subsequently grew, moving slowly from the middle Adriatic to the Greece region, while a geopotential high, initially amplifying to the west of the trough, moved eastward over southwest Europe. At the surface deep Mediterranean cyclone and a high pressure over southwestern European coast built up a large pressure gradient over the Adriatic (Fig. 6). Grubišić (1989) showed that this bora event was characterised by a deep uniform northeasterly flow. The maximum bora wind speeds were observed in this situation on 10 February on the northern Adriatic islands of Lošinj (Fig. 1, mean hourly wind speed $16.0 \mathrm{~ms}^{-1}$ ) and Krk (Fig. 1, mean hourly wind speed $15.5 \mathrm{~ms}^{-1}$ ). The bora conditions
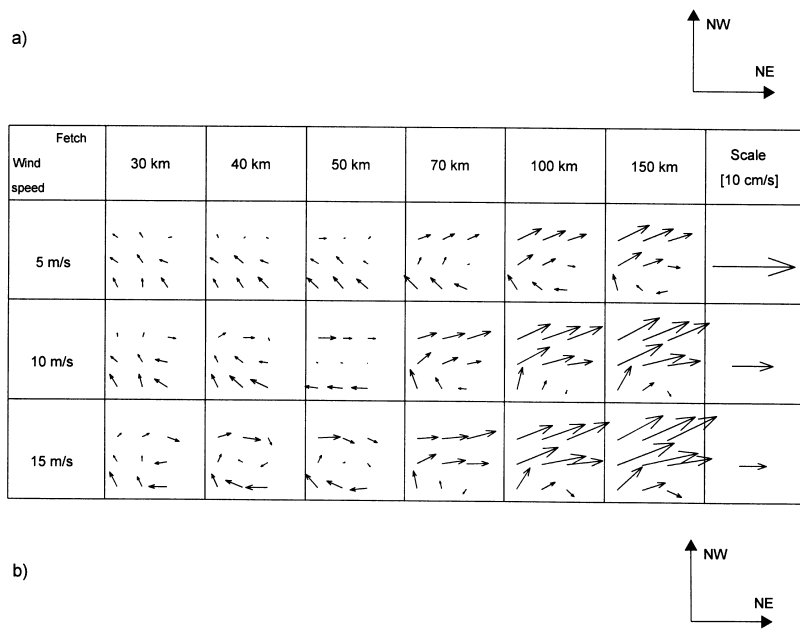

\begin{tabular}{|c|c|c|c|c|c|c|c|}
\hline $\begin{array}{l}\text { Fetch } \\
\text { Wind } \\
\text { speed }\end{array}$ & $30 \mathrm{~km}$ & $40 \mathrm{~km}$ & $50 \mathrm{~km}$ & $70 \mathrm{~km}$ & $100 \mathrm{~km}$ & $150 \mathrm{~km}$ & $\begin{array}{c}\text { scale } \\
{[10 \mathrm{~cm} / \mathrm{s}]}\end{array}$ \\
\hline $5 \mathrm{~m} / \mathrm{s}$ & $\therefore:$ & $\begin{array}{l}1 \\
\therefore \\
i\end{array}$ & $\begin{array}{l}-1 \\
-2 \\
-2\end{array}$ & $\vec{a} \overrightarrow{-}$ & $\begin{array}{l}\vec{\longrightarrow} \\
\vec{\rightarrow} \\
1,1\end{array}$ & $\begin{array}{l}\longrightarrow \rightarrow \\
\rightarrow\end{array}$ & $>$ \\
\hline $10 \mathrm{~m} / \mathrm{s}$ & i: & $i$ & $\begin{array}{l}\vec{a} \rightarrow \overrightarrow{ } \\
-\overrightarrow{-}\end{array}$ & $\begin{array}{l}\longrightarrow \rightarrow \\
\overrightarrow{1} \rightarrow\end{array}$ & $\overrightarrow{\longrightarrow \rightarrow}$ & $\rightarrow$ & $\rightarrow$ \\
\hline $15 \mathrm{~m} / \mathrm{s}$ & i 1 & 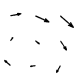 & $\mid \begin{array}{l}-2 \\
-2\end{array}$ & $\begin{array}{l}\longrightarrow \rightarrow \\
\vec{\longrightarrow} \rightarrow\end{array}$ & $\begin{array}{l}\rightarrow \rightarrow \\
\rightarrow \rightarrow\end{array}$ & $\frac{3}{3}$ & $p \rightarrow$ \\
\hline
\end{tabular}

Fig. 4. Surface currents (a) and currents at the seventh sigma level (b) in the area corresponding to the position of the gas field Ivana, obtained in the numerical experiments with climatological bora profiles calibrated to speeds of 5,10 and $15 \mathrm{~m} / \mathrm{s}$ at the Pula station and fetches of 30, 40, 50, 70, 100 and $150 \mathrm{~km}$.

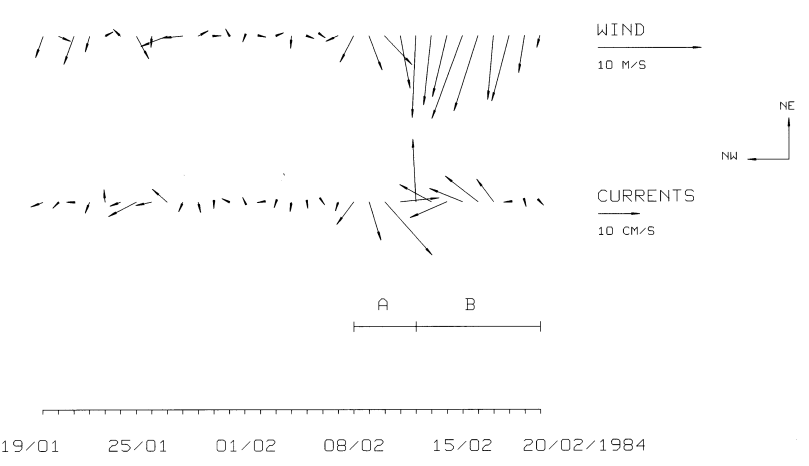

Fig. 5. Low-pass filtered series of the wind vectors registered at the height of $10 \mathrm{~m}$ above the ground at the meteorological station Pula airport and of the currents registered at 5-m depth at the gas field Ivana from 19 January to 19 February 1984. Also indicated are episodes A and B discussed in the text.

were also observed along the whole middle Adriatic as a part of the circulation connected with the cyclone centred over the southern Adriatic.

B) 12-19 February 1984 . This long-lasting bora remained severe during the whole episode while the upper level flow developed into a typical large-scale blocking pattern (Fig. 7). In the cases of long lasting severe bora conditions, this 
Case A

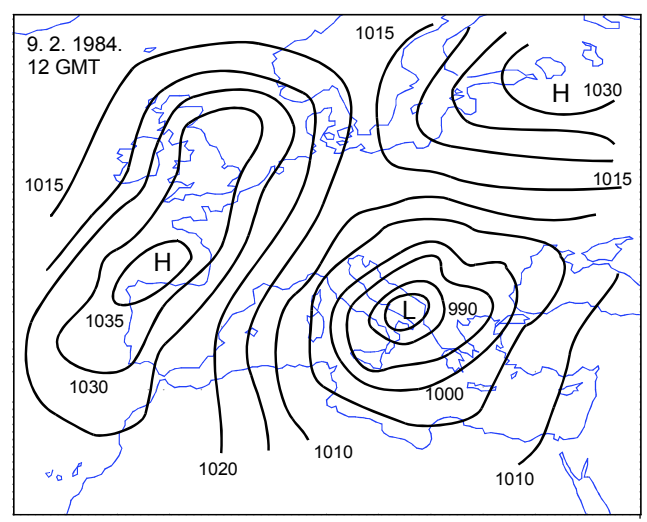

Fig. 6. Surface air pressure field on 9 February 1984.

temperature inversion is frequently observed and intensifies when a weakening upper tropospheric wind in a prefrontal stage turns to the southwesterly direction (Jurčec, 1989; Vučetić, 1988). A change in the upper level wind direction is associated with narrow trough extending from the northeastern Europe to the Adriatic region. The wind change to the northwesterly direction did not influence strongly the bora speed which rapidly decayed when the strong northeasterly flow behind the trough reached the upstream bora region. Cold air advection and stronger tropospheric northeasterly winds swept the inversion. Thus, cold air supply from the east associated with a continental anticyclone (Fig. 7) was not sufficient to oppose the effect of a strong unidirectional tropospheric northeasterly flow which apparently restrained the otherwise favourable bora conditions due to cold air supply (Jurčec, 1989; Bajić, 1990). Severe bora was observed in Senj (Fig. 1) with a maximum on 17 February (mean hourly wind speed $16.1 \mathrm{~ms}^{-1}$ ).

Although bora wind occurred in both situations, their different characteristics and spatial variability are obvious. The main reason for this is the difference in the vertical structure of the atmosphere. The first episode was characterised by a deep bora layer with cyclonic activity over the western Mediterranean and Genoa Bay, whereas the second one was accompanied by temperature inversion and southwesterly tropospheric wind above the shallow bora layer. Vertical profiles of potential temperature over Zagreb, Udine and Milano (Figs. 8 and 9) show further differences between the two situations.

Thus, the vertical profile of the potential temperature in the second situation indicates a definite descent of lower isentropic surfaces (those below $282 \mathrm{~K}$ ) from the upstream to the downstream bora region (Fig. 9). At the same time, descent of upper isentropes did not exist. The region of isentrope splitting seems to have filled the gap between the descending bora air and the less disturbed condition aloft. In the first bora situation vertical structure was quite different (Fig. 8). A less pronounced descent of isentropes existed in the entire troposphere on 8 February. However, this feature almost
Case B

a)

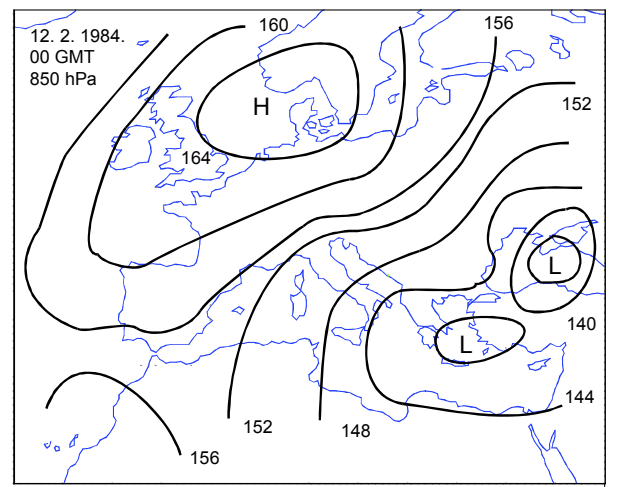

b)

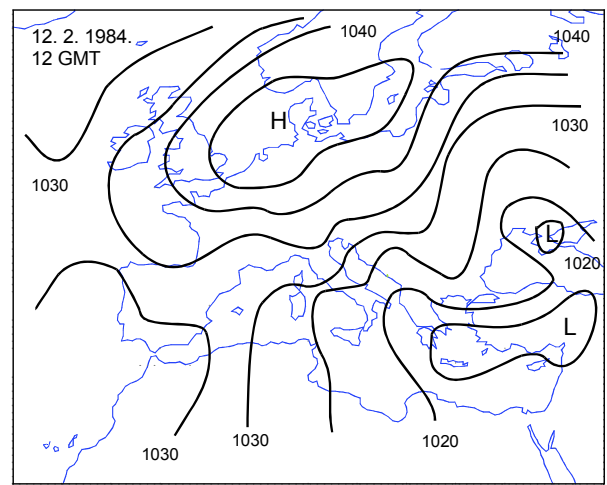

c)

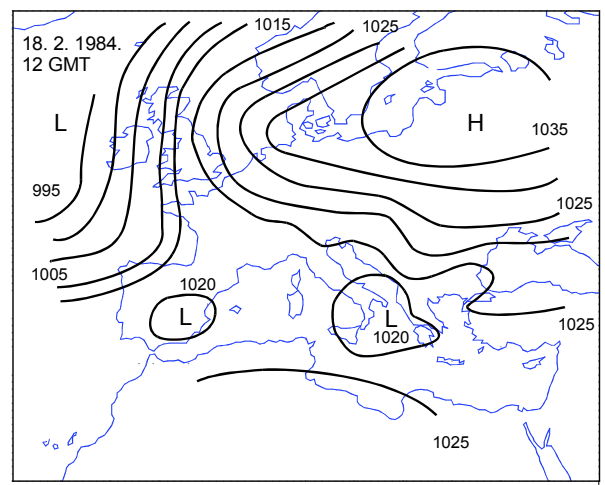

Fig. 7. Absolute topography AT $850 \mathrm{hPa}$ on 12 February 1984 (a), surface air pressure field on 12 February 1984 (b), and surface air pressure field on 18 February 1984 (c).

disappeared on 9 February (vertical profiles of potential temperature in Udine and Milano are almost the same).

Differences that arose from different isentropic structures of two studied bora episodes can be explained using Smith's (1985) hydraulic model for severe downslope winds, illustrated in Fig. 10. When the bora layer with velocity $U$ and height $H_{0}$ arrives at the obstacle with height $h$, splitting of the isentropes occurs. Critical isentrope $\left(\theta_{c}\right)$ descend $\left(\delta_{c}\right)$ in the upstream region, observed both from aerological and aircraft measurements (Smith, 1987; Bajić, 1988; Vučetić, 1988), results in downstream acceleration for two reasons. Firstly, the conservation of mass flow rate between the rising terrain and the descending isentropes would require flow 
Case A
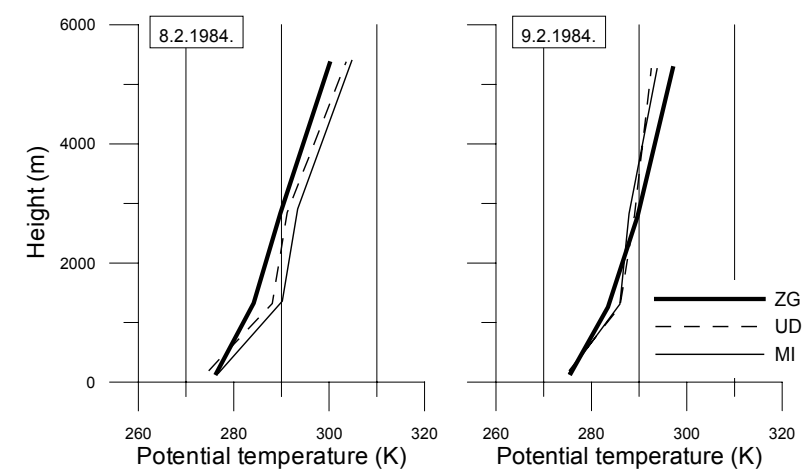

Fig. 8. Vertical profiles of potential temperature at Zagreb (ZG), Udine (UD) and Milano (MI) on 8 and 9 February 1984 at 00 UTC.

Case B

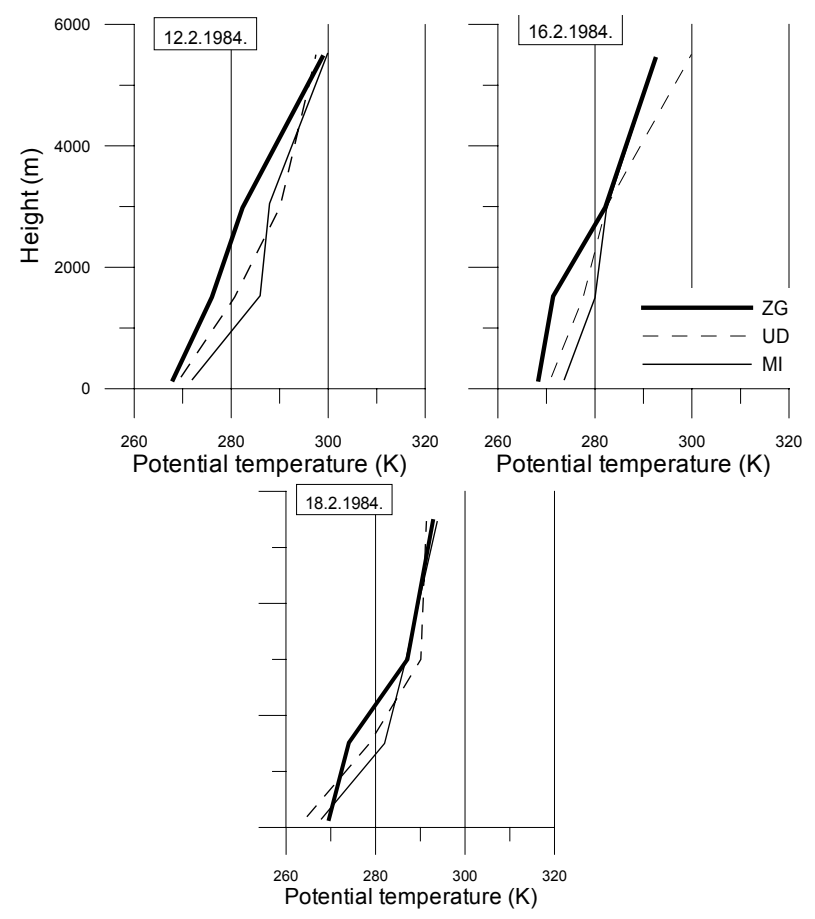

Fig. 9. Vertical profiles of potential temperature at Zagreb (ZG), Udine (UD) and Milano (MI) on 12, 16 and 18 February 1984 at 00 UTC.

acceleration. Secondly, the descending isentropes produce a horizontal density gradient that hydrostatically gives rise to a pressure gradient below. This pressure gradient is directly responsible for the flow acceleration. The local descent of isentropes implies both local baroclinicity, which generates horizontal components of vorticity, and differential vertical motion, which tilts the horizontal vorticity components into the vertical (Dempsey, 1989). Consequently, since no isentropic surface descend was observed during the first bora event, it could be concluded that the conditions did not support significant flow acceleration from the upstream to down-

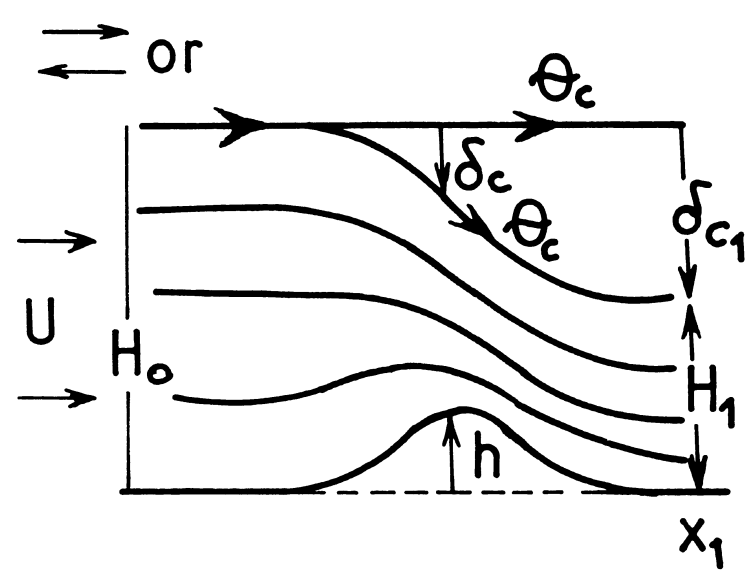

Fig. 10. Schematics of Smith's (1985) hydraulic model for severe downslope winds.

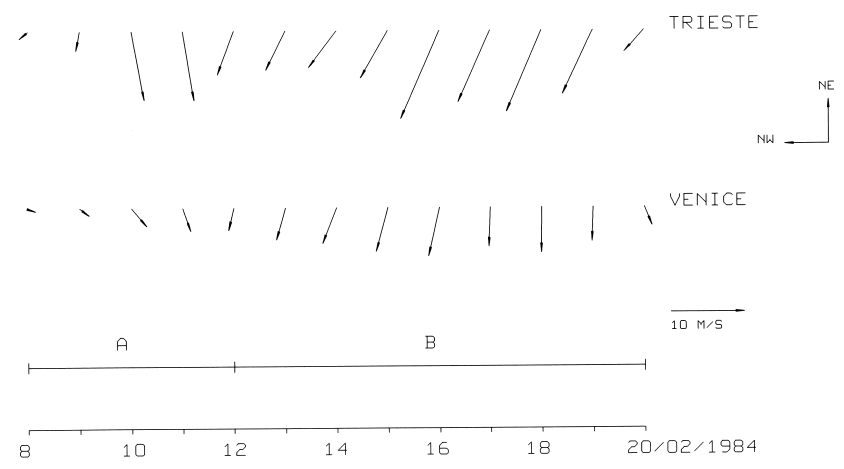

Fig. 11. Low-pass filtered series of the wind vector at the meteorological stations Trieste (up) and Venice (down). A and B indicate episodes discussed in the text.

stream bora region at the time. Moreover, investigations of time-dependent downslope winds (Bacmeister and Pierrehumbert, 1988) showed that for a higher atmospheric bora layer stronger energy dissipation may occur, leading to lower acceleration at the surface. This agrees with our results, and implies that the first bora case with a higher incoming layer was characterised by lower speeds and faster offshore decay.

Lower wind speeds during the period $\mathrm{A}$ in comparison with the period B are easily observed from the wind data collected at meteorological stations Pula, Trieste and Venice (Figs. 5 and 11). A stronger offshore speed decrease during the first bora episode is confirmed by a comparison between northeasterly wind components (Table 1) and wind vectors (Fig. 11) at the meteorological stations Trieste and Venice, positioned on the opposite Adriatic coasts (Fig. 1). Although the distance at which the bora becomes zero depends on the position where it was determined, the presented results agree with the characteristics of some bora situations in which the bora speed becomes zero at short offshore distances (Penzar et al., 2001; Poulain and Raicich, 2001). On the other hand, the second long-lasting bora, which induced upwind surface currents, had small offshore speed decay (Table 1 and 
Table 1. Northeasterly wind means and standard deviations at Trieste and Venice and corresponding differences for two bora cases: 8-11 February (A) and 12-19 February 1984 (B). $\mathrm{N}$ is the number of hourly values included in the analysis.

\begin{tabular}{llll}
\hline & Mean $\left(\mathrm{ms}^{-1}\right)$ & $\mathrm{STD}\left(\mathrm{ms}^{-1}\right)$ & $\mathrm{N}$ \\
\hline Case A & & & \\
\hline NE & & 3.331 & 96 \\
NEIESTE & 6.24 & 1.020 & 96 \\
NE & 2.02 & 2.424 & 96 \\
\hline Case B & 4.22 & & \\
\hline NE & & 3.256 & 192 \\
NERIESTE-VENICE & 7.08 & 1.496 & 192 \\
NE & 4.78 & 2.091 & 192 \\
\hline
\end{tabular}

Fig. 11). Due to strong alongshore variability, with larger velocities off Trieste and Senj and smaller velocities at the cross section of the Rovinj - Po River, this type of bora induced cyclonic gyre in the northernmost part of the Adriatic. The gas field Ivana was then in the area of the counter current. We hypothesise that the first bora, due to its lower speeds and strong offshore decrease, was not able to generate cyclonic gyre and, therefore, the surface current at the gas field Ivana was in the wind direction.

\section{Conclusions}

Numerical experiments with different bora spatial distributions indicate that the surface current direction in the northern Adriatic depends on the bora intensity and distance from the eastern coast at which the bora speed vanishes. Bora with greater wind speeds off Trieste and Senj and smaller speeds at the cross section of the Rovinj - Po River and with slower offshore decay, induces a cyclonic gyre in the northernmost part of the Adriatic. The transect Rovinj - Po River is in the area of the counter current, which is formed in the southern part of the cyclonic gyre. Bora episodes with lower speeds and high offshore decay are not able to generate the cyclonic gyre, and therefore they can only induce downwind currents in the limited offshore area. It is important to notice that in the eastern part of the studied transect, which coincides with the position of the gas field station Ivana, strong bora with fast offshore decay has the same effect as the bora having low intensity and slow offshore decay. The stresses acting on the sea surface are of comparable strength in these cases.

Eulerien current measurements at the gas field Ivana indicate the occurrence of the oppositely directed surface currents during two bora episodes. These measurements and detailed analyses of synoptic situations offer possible support of the numerical model results.

The deep bora layer, with its centre of cyclonic activity over the western Mediterranean and Genoa Bay, was accompanied by downwind surface currents at the gas field Ivana in the period 8-11 February 1984. On the other hand, cyclonic development in the period 12-19 February 1984, which was characterised by inversion and southwesterly tropospheric wind above a shallow bora layer, induced upwind surface currents.

The main difference between the two studied bora episodes was their vertical development. The well expressed descent of isentropic surfaces in the bora layer observed in the second situation is, according to Smith's (1985) hydraulic theory, an indicator of significant flow acceleration from the upstream to downstream bora region and consequently, slower offshore bora decay. On the other hand, the vertical atmospheric structure in the first bora episode gives no evidence of significant flow acceleration, which agrees with its lower speeds observed at the meteorological stations Pula, Trieste and Venice and faster offshore decay confirmed by the comparison of the wind data from two meteorological stations positioned on the opposite Adriatic coasts. Moreover, our results match investigations of nonstationary downslope winds, which indicate stronger energy dissipation in the case of stronger vertical development.

Finally, let us emphasise the connection between surface wind characteristics, vertical structure of the atmosphere and corresponding current directions. The first bora episode characterised by higher atmospheric vertical development, lower upwind acceleration and stronger offshore decay induced downwind currents, whereas the second one, limited to a shallow atmospheric layer and having significant upwind acceleration, induced the cyclonic gyre in the northernmost part of the Adriatic Sea with counter currents affecting the gas field Ivana station.

Although the presented numerical experiments give quite interesting results, the use of space- and time-varying wind stresses and heat fluxes from mesoscale meteorological models (e.g. Beg Paklar et al., 2001; Pullen et al., 2003), instead of simple forcing with suddenly applied climatological wind speed profile, would improve findings as well as our understanding of the bora's influence on the Adriatic dynamics. The study of the detailed structure of the sea surface temperature could also contribute to this understanding, since Enger and Grisogono (1998) have shown that offshore bora extent depends on the difference between the sea surface and air temperature.

Acknowledgements. Meteorological and Hydrological Service of the Republic of Croatia kindly provided wind data from Croatian meteorological stations. We are grateful to F. Raicich from Istituto Talassografico Sperimentale in Trieste and L. Zampato from Comune di Venezia for providing us with the wind data from Italian stations. We would also like to thank J. Miljak for his helpful discussion of the synoptic situations. The work was supported by the Ministry of Science, Education and Sports of the Republic of Croatia. We thank two anonymous referees for their constructive suggestions.

Topical Editor N. Pinardi thanks three referees for their help in evaluating this paper. 


\section{References}

Bacmeister, J. T. and Pierrehumbert, R. T.: On high-drag states of nonlinear stratified flow over an obstacle, J. Atmos. Sci., 45, 6380, 1988.

Bajić, A.: The strongest bora event during ALPEX-SOP, Rasprave (Papers), 23, 1-12, 1988.

Bajić, A.: Spatial bora variations in relation to cold air outbreak and surface pressure gradient, Rasprave (Papers), 25, 13-24, 1990.

Bajić, A. and Glasnović, D.: Impact of severe Adriatic Bora on traffic, Proceedings 4th European Conference on Application of Meteorology - CD, Norrköping, Sweden, 13-17 September 1999, 46-48, 1999.

Beardsley, R. C., Boicourt, W. C., Huff, L. C., McCullough, J. R., and Scot, J.: CMICE: A near-surface current meter intercomparison experiment, Deep Sea Res., 28, 1577-1603, 1981.

Beg Paklar, G., Isakov, V., Koračin, D., Kourafalou, V., and Orlić, M.: A case study of bora-driven flow and density changes on the Adriatic shelf (January 1987), Cont. Shelf Res., 21, 1751-1783, 2001.

Blumberg, A. F. and Mellor, G. L.: A description of a threedimensional coastal ocean circulation model, In: Heaps, N. S. (Ed.), Three Dimensional Coastal Ocean Models, Coastal and Estuarine Science 4, AGU, Washington, D.C. 16, 1987.

Bone, M.: Development of a non-linear levels model and its application to bora-driven circulation on the Adriatic shelf, Estuar. Coast and Shelf Sci., 37, 475-496, 1993.

Brzović, N.: Factors affecting the Adriatic cyclone and associated windstorms, Contr. Atmos. Phys., 72, 51-65, 1999.

Deacon, E. L. and Webb, E. K.: Interchange of properties between sea and air, In: Hill M. N. (Ed.), The Sea, Vol 1. WileyInterscience Publication, New York, 43-315, 1962.

Dempsey, D. P.: Insights into Alpine lee cylogenesis from numerical simulations of moderately rotating, low Froude number first past three-dimensional obstacles, International Conference on Mountain Meteorology and ALPEX, Garmisch-Partenkirchen, 5-9 June 1989, 87-89, 1989.

Enger, L. and Grisogono, B.: The response of bora-type flow to sea surface temerature, Quart. J. R. Meteor. Soc., 124, 1227-1244, 1998.

Gould, W. J.: Effects of non-linearities of current meter compasses, Deep Sea Res., 20, 423-427, 1973.

Grubišić, V.: Application of the hydraulic theory in cases of bora with strong upstream flow, Rasprave (Papers), 24, 21-28, 1989.

Jurčec, V.: The Adriatic frontal bora type, Rasprave (Papers), 23, 13-26, 1988.

Jurčec, V.: Severe Adriatic bora storms in relation to synoptic developments, Rasprave (Papers), 24, 11-20, 1989.

Kuzmić, M.: Exploring the effects of bora over the Northern Adriatic - CZCS imagery and a mathematical model prediction, Int. J. Rem. Sens., 12, 1, 207-214, 1991.

Long, R. R.: Some aspects of the flow of stratified fluids, II, Experiments with a two fluid system, Tellus, 6, 97-115, 1954.

Makjanić, B.: Bora, sirocco and etesian winds (in Croatian), Prilozi poznavanju vremena i klime SFRJ 5, 1-56, 1978.

Mellor, G. L.: An equation of state for numerical models of ocean and estuaries, J. Atmos. Ocean. Technol., 8, 609-611, 1991.

Mellor, G. L. and Blumberg, A. F.: Modeling vertical and horizontal diffusivities with the sigma coordinate system, Mon. Weather Rev., 113, 1379-1383, 1985.
Mellor, G. L. and Yamada, T.: Development of turbulent closure models for geophysical fluid problems, Rev. Geophys. Space Phys., 20, 851-875, 1982.

Miljak, J.: Dependance of the wind speed on the offshore distance (in Croatian), B. Sc. Thesis, University of Zagreb, 47, 1982.

Orlić, M., Kuzmić, M., and Vučak, Z.: Wind-curl currents in the Northern Adriatic and formulation of bottom friction, Oceanol. Acta, 9, 425-431, 1986.

Orlić, M., Kuzmić, M., and Pasarić, Z.: Response of the Adriatic Sea to the bora and scirocco forcing, Cont. Shelf Res., 14, 91116, 1994.

Penzar, B., Penzar, I., and Orlić, M.: Weather and climate of the Croatian Adriatic (in Croatian), Feletar, Hrvatski hidrografski institut, Split, 258, 2001.

Polli, S.: La Bora nei golfi di Trieste e Venezia, Boll. Soc. Ital. Geof. Meteorol., 6, 2-3, 1956.

Poulain, P-M. and Raicich, F.: Forcings, In: Cushman-Roisin, B., Gačić, M., Poulain, P-M., and Artegiani, A. (Eds.): Physical Oceanography of the Adriatic Sea: Past, Present and Future, Kluwer Academic Publishers, Dordrecht, 45-65, 2001.

Pullen, J., Doyle, J. D., Hodur, R., Ogston, A., Book, J. W., Perkins, H., and Signell, R.: Coupled ocean-atmosphere nested modeling of the Adraitic Sea during winter and spring 2001, J. Geophys Res., 108, No.C10, 3320, doi:10.1029/2003JC001780, 2003.

Shapiro, R.: Smoothing, filtering and boundary effects, Rev. Geophys. Space Phys., 8, 359-387, 1970.

Sherwin, T. J.: Measurements of current speed using an Aanderaa RCM4 current meter in the presence of surface waves, Cont. Shelf Res., 8, 131-144, 1988.

Smirčić, A., Gačić, M., and Dadić, V.: Surface waves, Acta Adriat., 37, 17-34, 1996.

Smith, R. B.: On severe downslope winds, J. Atmos. Sci., 42, 2598 2603, 1985.

Smith, R. B.: Aerial observations of the Yugoslavian bora, J. Atmos. Sci., 44, 269-297, 1987.

Smith, R. B. and Sun, J.: Generalized hydraulic solutions relevant to severe downslope winds, J. Atmos. Sci., 44, 2934-2939, 1987.

Sounders, P. M.: Near-surface current measurements, Deep Sea Res., 23, 249-257, 1976.

Sounders, P. M.: Overspeeding of a Savonius rotor, Deep Sea Res., 27, 755-759, 1980.

Stravisi, F.: Bora driven circulation in Northern Adriatic, Boll. Geofis. Teor. Appl., 19, 95-102, 1977.

Sturm, B., Kuzmić, M., and Orlić, M.: An evaluation and interpretation of CZCS-derived patterns on the Adriatic shelf, Oceanol. Acta, 15, 13-23, 1992.

Thompson, R. O. R. Y.: Low-pass filters to suppress inertial and tidal frequencies, J. Phys. Oceanogr., 13, 1077-1083, 1983.

Vučetić, V.: Bora on the Northern Adriatic, 12-18 April 1982, Rasprave (Papers), 23, 27-44, 1988.

Yoshino, M. M.: Local Wind Bora, University of Tokio Press, Tokio, 289, 1976.

Yoshino, M. M., Yoshino, M. T., Yoshimura, M., Mitsui, K., Urushibara, K., Ueda, S., Owada, M., and Nakamura, K.: Bora regions as revealed by wind-shape trees on the Adriatic Coast, In: Yoshino, M. M. (Ed.): Local Wind Bora, University of Tokio Press, Tokio, 289, 1976.

Zore-Armanda, M. and Gačić, M.: Effects of bora on the circulation in the North Adriatic, Ann. Geophys., 5, 93-102, 1987. 